MINERALOGIA, 42, No 2-3: 113-120 (2011)

DOI: 10.2478/v10002-011-0010-y

www.Mineralogia.pl

MineRALOgICAL SOCIETY OF POLAND

Polskie TOWARZYSTWO MINERALOGICZNE

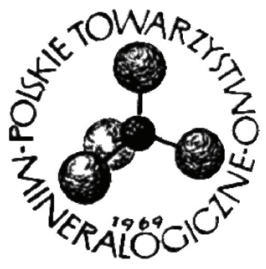

Short note

\title{
Note on the stable isotope values of vein calcite in the El-Seboah peralkaline granite (SW Egypt)
}

\author{
Kamaleldin M. HASSAN ${ }^{1}$

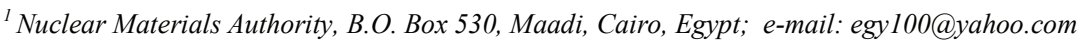

Received: July 27, 2011

Received in revised form: February 8, 2012

Accepted: March 10, 2012

Available online: March 25, 2012

\begin{abstract}
Stable isotope data for carbon $\left(\delta^{13} \mathrm{C}\right)$ and oxygen $\left(\delta^{18} \mathrm{O}\right)$ are used to constrain the environments of calcite formation in two veins in the El-Seboah peralkaline granite in south-western Egypt. Vein I with calcitemagnetite-goethite-hematite-quartz, and vein II with calcite-magnetite-goethite-kaolinite-hematite-quartz are texturally distinct. The calcite of each vein has characteristic $\delta^{13} \mathrm{C}$ - and $\delta^{18} \mathrm{O}$-values: +0.32 and $-7.28 \%$ for vein I and +1.16 and $-1.21 \%$ for vein II, respectively. The observed differences between the $\delta^{13} \mathrm{C}$ values of the two veins indicate that they represent two separate systems of primary dissolved inorganic carbon formed at or near equilibrium with atmospheric $\mathrm{CO}_{2}$. The $\delta^{18} \mathrm{O}$ values, on the other hand, indicate calcite deposition from meteoric waters which were fresh for vein I and brackish for vein II.
\end{abstract}

Key-words: $\delta^{13} \mathrm{C}, \delta^{18} \mathrm{O}$, carbonate-hosting veins, peralkaline granite, Egypt

\section{Introduction}

Stable isotope data $\left(\delta^{13} \mathrm{C}\right.$ and $\left.\delta^{18} \mathrm{O}\right)$ are presented for calcite occurring in two small, distinctive veins from the El-Seboah peralkaline granite. The first, vein I, is massive, coarse-grained and consists of milky quartz, red-colored iron oxide crystals with some carbonates. The second, vein II, is porous, fine grained and consists of quartz, violetcolored iron oxides, clay and carbonates. Both veins display enriched total gamma-ray radiation (up to three orders of magnitude more than the host granite), with vein I having high radiation counts. The radioactivity in the area is due mainly to thorium and, to a lesser 
extent, uranium (Hassan 2005, 2009, 2010). The nearest carbonate outcrop to the site of the veins is Sinn el-Keddab plateau $\sim 80$ kilometers to the north (Fig. 1). The ground water in the region forms part of the so-called Nubian aquifer. At present, rains occur only every three to four years in this region (Said 1969).

\section{A}

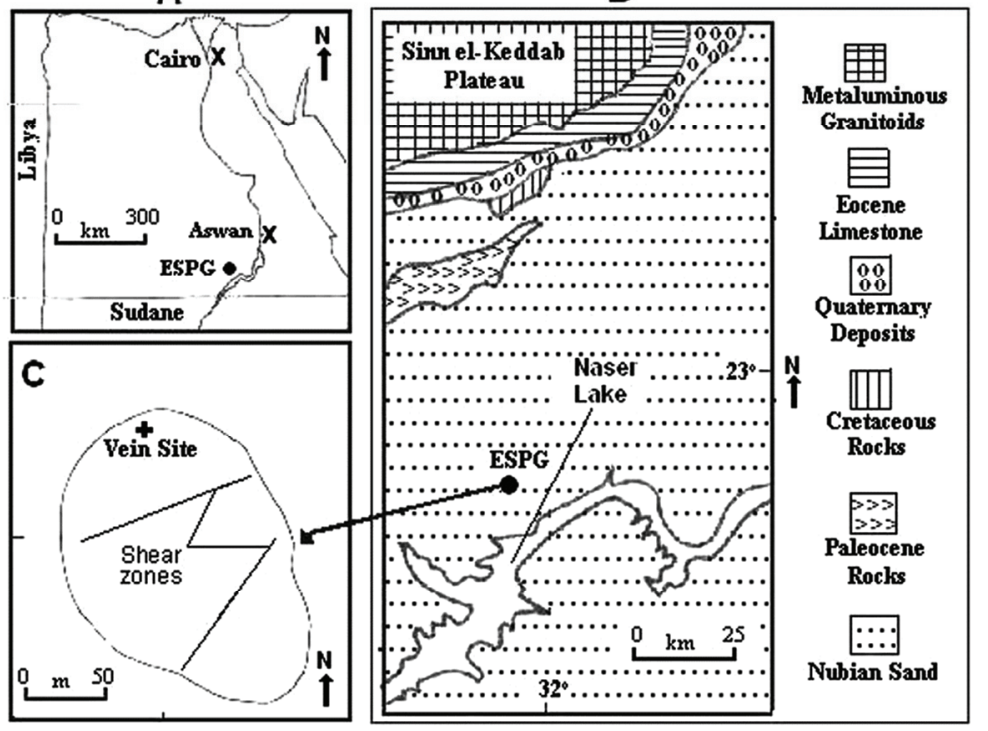

Fig. 1. Location of El-Seboah peralkaline granite (ESPG), (B) geologic map showing the major rock units in the region, and (C) simplified geologic map of ESPG.

Samples of both veins were collected in the field and studied in the laboratory. The study included the identification of minerals and textures, and stable isotope analysis of carbonate. The aim was to establish the nature of carbonate present. As a consequence, it has been possible to trace the water- and carbon sources from which the carbonate derived. Carbonate stable-isotope data have been used as paleoenvironmental indicators in both sedimentary basins (e.g. Shemesh et al. 1992) and igneous systems (e.g. Larson, Tullborg 1984; Tullborg 1989; Drake, Tullborg 2009; Sandström, Tullborg 2009).

\section{Host rock}

The El-Seboah peralkaline granite, a suitable environment for uranium, thorium, relatively rare- and rare elements, is a pear-like intrusion rising above the Nubian sand in the south Western Desert, Egypt. It is a homogeneous body consisting mainly of quartz, feldspars and aegirine cut by occasional peralkaline dykes. It may be classified as one of the so-called " $\mathrm{g}_{\gamma}$ " granites, a type of quartz syenite and granitoid having a peralkaline tendency that is common in ring complexes and dike-like intrusions dating from the end of Precambrian to the Paleozoic in Egypt (List et al. 1989). The El-Seboah granite contains several zones of fractures of which most strike north-east (Hassan 2005). The fracture 
zones are filled with pockets of hematite-goethite-aegirine-quartz displaying anomalously high levels $(<1800$ counts per second) of total field gamma-ray radiation though lacking any obvious radioactive mineralization. The radiation is, in fact, due to thorium and, to a lesser extent, uranium. The radioactive elements reside in trace mineral phases and in iron compounds (Hassan 2005). These radioactive pockets are highly oxidized, with ferric ironto-total iron ratios of $\sim 95-99.7 \%$ (Hassan 2010).

\section{Analytical methods}

The vein samples were examined by optical microscopy, and by X-ray diffraction (XRD) using a Philips diffractometer (type PW 1399) with Co-K $\mathrm{K}_{\alpha}$ radiation $(\lambda=1.79 \AA$ Á). For determination of carbonate oxygen and carbon isotope ratios, aliquots of the bulk samples were reacted with $100 \% \mathrm{H}_{3} \mathrm{PO}_{4}$ and the evolved $\mathrm{CO}_{2}$ purified in a high-vacuum gas-transfer system, USA. The ratios were determined using a Finnigan isotope ratio mass spectrometer (IRMS) at the Stable Isotope Laboratory, University of Michigan. Results are reported in delta $(\delta)$ notation in units per mil (\%) relative to the Vienna Pee Dee belemnite (V-PDB) carbonate standard. Measured precision was maintained at better than $\pm 0.1 \%$ ov-PDB for both ratios.

\section{Results and discussion}

Vein I samples are composed mainly of quartz and opaque minerals (mainly iron oxides) with minor carbonates (Fig. 2a, b). Quartz occurs as medium- to coarse-grained anhedral interlocking crystals displaying sutures and wavy extinction, in granular mosaics and in micro-veinlets of cryptocrystalline quartz. Iron oxides present as long prismatic crystals and as rhombs (pseudomorphs of pyroxene) usually include carbonates along fractures and in cavities. Vein II, on the other hand, is characterized by spherulitic texture (Fig. 2c). The spherulites are fine- to medium sized, composed mainly of quartz and clay in radiating forms. Opaque minerals (mainly iron oxides) and carbonates are also seen. The iron oxides occur as aggregates of fine-spheres following the radiating forms. The carbonates occur as fine anhedral forms and have a high birefringence (Fig. 2d). Finegrained quartz crystals occupy the spaces between spherulites.

In addition to the major minerals quartz and hematite, and kaolinite (in vein II only), calcite, goethite and magnetite were identified as minor phases by XRD. Representative examples of XRD patterns with mineral identifications are given in Figure 3. The identified calcite has major diffraction peak values of $3.035 \AA$ which according to others (e.g. Goldsmith et al. 1961) indicate little if any magnesium substitution. Calcite low in magnesium tends to be chemically stable. This implies that the low-Mg carbonates in the veins are probably yielding unchanged isotopic compositions reflecting initial depositional conditions.

Vein-calcite carbon and oxygen isotopic compositions are plotted in Figure 4 along with isotopic compositions for tufa deposits, marine carbonates, recent land snail shells from the Sinn el-Keddab plateau (Hassan 2006, 2012). The data indicate two distinct groups in which the calcite of each vein has a characteristic isotopic composition. Vein I differs by $\sim 0.8 \%$ v-pDB in $\delta^{13} \mathrm{C}$ and by $\sim 6$ in $\delta^{18} \mathrm{O} \%$ ov-pDB from vein II. The $\delta^{13} \mathrm{C}$ and $\delta^{18} \mathrm{O}$ differences 
between veins I and II indicate that they are two separate systems which developed under different hydrologic conditions. To asses the factors potentially influencing the isotopic compositions of the calcite-vein fillings, a brief discussion of the causes of change in $\delta^{13} \mathrm{C}$ and $\delta^{18} \mathrm{O}$ is appropriate here.

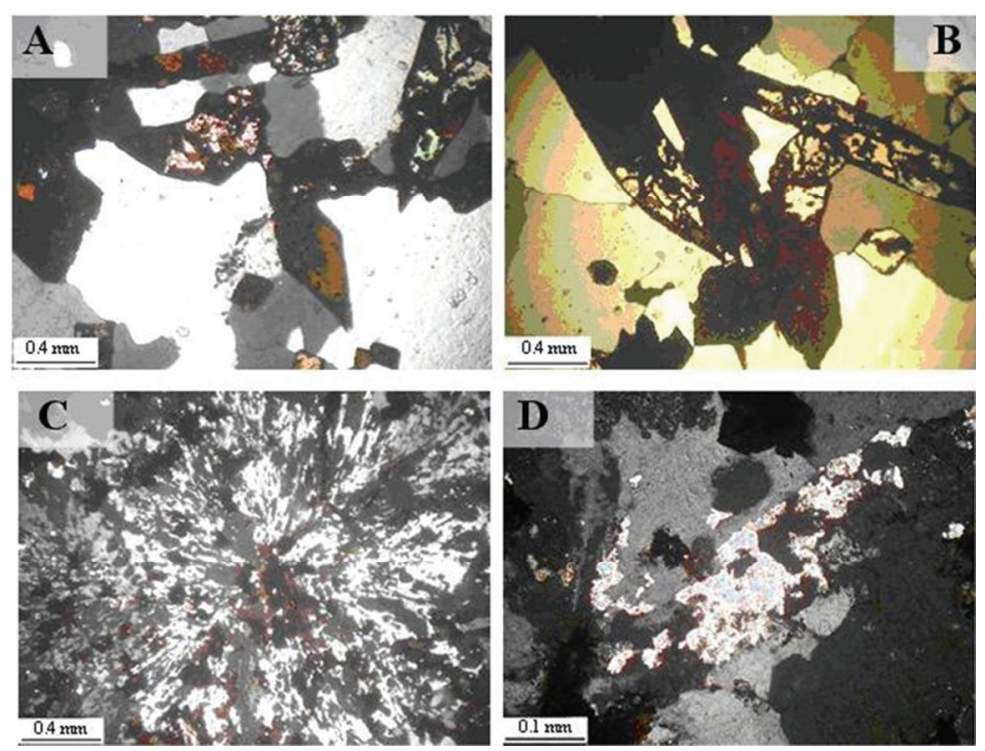

Fig. 2. Photomicrographs taken for samples of vein I (A, B) and vein II (B, C) in the cross-polarized light view. (A) and (B) showing rhombs and long prismatic crystals of iron oxides containing calcite and surrounded by quartz. (C) Spherulitic texture. (D) Aggregates of calcite (pearl white), iron oxides (dark) and quartz (grey). Note: calcite has very high birefringence.

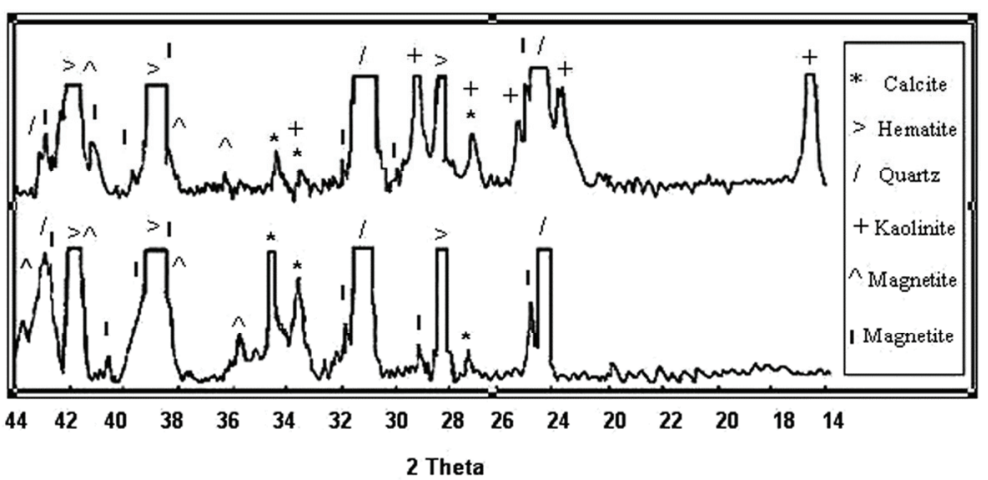

Fig. 3. Representative XRD patterns for vein I (lower) and vein II (upper).

Carbon isotopes in carbonate are related to the isotopic composition of the dissolved inorganic carbon (DIC) from which the carbonate derived. Carbon in primary carbonates formed from a uniform DIC at the atmosphere-surface water boundary varies only slightly 
in its isotopic composition; most cases lie range $\delta^{13} \mathrm{C}$ range $=0 \pm 4 \%$ орDB (e.g. Craig 1953). Deviations from this range towards strongly negative $\delta^{13} \mathrm{C}$ values are thought to be formed from DIC released from various sources, including but not limited to, magmatic assimilation, metamorphism (Kontak, Kerrich 1997; Negga et al. 1986; Ripley, Taib 1989), aerobic metabolism, and oxidation of methane (e.g. Clayton 1994). Deviations towards strongly positive $\delta^{13} \mathrm{C}$ values in carbonates have been attributed to processes such as fermentation of organic acids, $\mathrm{CO}_{2}$ reduction and excessive evaporation (e.g. Clayton 1994). Thus, the $\delta^{13} \mathrm{C}$ for the vein I calcite (ranging from $0-0.46 \%{ }_{\mathrm{V}-\mathrm{PDB}}$; average $0.32 \% \mathrm{ov}_{\text {-PDB }}$ ) and for vein II (ranging from 0.94-1.32\% ${ }_{\mathrm{V}-\mathrm{PDB}}$; average $1.16 \% \mathrm{ov}_{\mathrm{V}-\mathrm{PDB}}$ ) suggest contrasting primary carbon sources. These $\delta^{13} \mathrm{C}$ differences could be intrinsic compositional features reflecting different sources. They could also result from the influence of temperature on the partial pressure of carbon dioxide $\left(\mathrm{pCO}_{2}\right)$ in the waters (i.e. higher $\mathrm{pCO}_{2}$ in cold water). Systematic differences in $\delta^{13} \mathrm{C}$ of $<1.16 \%$ v-PDB in vein calcite have been attributed to fractionation during $\mathrm{CO}_{2}$ release from the vein-forming solution (Shemesh et al. 1992).

Oxygen isotope ratios in carbonate reflect both temperature and the isotopic content of the source water. The temperature dependence of $\delta^{18} \mathrm{O}$ in the $\mathrm{CaCO}_{3}{ }^{16}+\mathrm{H}_{2} \mathrm{O}^{18} \leftrightarrows \mathrm{CaCO}_{3}{ }^{18}$ $+\mathrm{H}_{2} \mathrm{O}^{16}$ equilibrium system can be described as follows (Craig, Gordon 1965):

$$
\mathrm{T}\left({ }^{\circ} \mathrm{C}\right)=\left[16.9-4.2\left(\delta_{\mathrm{C}}-\delta_{\mathrm{W}}\right)+0.13\left(\delta_{\mathrm{C}}-\delta_{\mathrm{W}}\right)^{2}\right]
$$

where $\delta_{\mathrm{C}}$ is the delta of carbonate relative to the V-PDB standard and $\delta_{\mathrm{W}}$ is the delta value relative to the Vienna Mean Ocean Water standard (V-SMOW) of the water in which the carbonate precipitated. In order to use this equation for estimating paleotemperatures based on the vein $\delta^{18} \mathrm{O}$ values (Fig. 4), an additional assumption about the isotopic composition of the source water at the time of calcite formation is required. Unfortunately, isotope analysis of water inclusions from the samples studied, which would have given a better picture of the paleohydrologic parameters, was not possible. However, if it is assumed that temperature was the dominant factor in the observed $\delta^{18} \mathrm{O}$ variations (Fig. 4) and that the mineralizing waters were isotopically similar to those of the Nubian aquifer $\left(\delta^{18} \mathrm{O}=\right.$ -11.1\%ov-smow; Sultan et al. 1998), the equation provides equilibrium temperatures at which the calcite of vein I and vein II formed of $\sim 3^{\circ} \mathrm{C}$ and $-12^{\circ} \mathrm{C}$, respectively. Different formation temperatures are derived for vein I $\left(\sim 15^{\circ} \mathrm{C}\right)$ and vein II $\left(\sim-12^{\circ} \mathrm{C}\right)$ if it is assumed that the mineralizing waters were modern rain $\left(\delta^{18} \mathrm{O}=-7.84 \%\right.$ ov-smow; Al-Gamal 1997). Hence, only the vein I calcite is combatable with formation from ground- and rain water in the region.

Vein-calcite $\delta^{18} \mathrm{O}$ values may be used to determine whether the mineralizing water was high temperature-, fresh- or saline. High-temperature waters, particularly magmatic fluids, are exceptionally enriched in ${ }^{18} \mathrm{O}$ and, thus, carbonates derived from them will have strongly positive $\delta^{18} \mathrm{O}$ values ranging up to $\sim+28 \%{ }_{\mathrm{PDB}}$ (Kontak, Kerrich 1997). In contrast, carbonates precipitated from fresh waters usually have negative $\delta^{18} \mathrm{O}$ values from $\sim-2.5$ to $-17.5 \%$ opd depending, e.g. on the composition of source rocks and water inputs, open-or closed basin situation, evaporation rate, etc. (Clayton, Degens 1959). Relative to freshwater carbonates, carbonates formed in saline lacustrine basins are characterized by high ${ }^{18} \mathrm{O}$ contents $<+8.86 \%$ рерв (Valero-Garcēs et al. 1999). Therefore, the $\delta^{18} \mathrm{O}$ values of vein I 
calcite (ranging from -7.16 to $-7.52 \%{ }_{\mathrm{V}-\mathrm{PDB}}$; average $-7.28 \% \mathrm{ov}_{\mathrm{PDB}}$ ) suggest fresh water conditions while those of vein II calcite (ranging from -1.03 to $-1.37 \%$ ov-PDB; average $-1.21 \%{ }_{\mathrm{V}-\mathrm{PDB}}$ ) suggest slightly saline meteoric waters. The increase in $\delta^{18} \mathrm{O}$ in vein I relative to vein II is consistent with the latter containing kaolinite and having high sodium contents $\left(\mathrm{NaO}_{2}=4000 \mathrm{ppm}\right)$. Studies indicate that saline waters in equilibrium with kaolinite in warm climates become enriched in ${ }^{18} \mathrm{O}$ due to high temperature exchange (minimum fractionation) with kaolinite which is relatively rich in ${ }^{18} \mathrm{O}$; thus carbonates formed under these circumstances become ${ }^{18} \mathrm{O}$-rich (Truesdell, Hulston 1980).



Fig. 4. Plot of $\delta^{13} \mathrm{C}$ vs. $\delta^{18} \mathrm{O}$ for veins I and II and for land snail, marine and tufa carbonates from the Sinn-el Keddab Plateau.

As shown in Figure 4, the calcite of veins I and II is enriched in ${ }^{13} \mathrm{C}$ relative to tufa- and land-snail carbonates from the Sinn el-Keddab plateau. The tufa, in spite of ${ }^{13} \mathrm{C}$ depletions due to organic inputs, could be related to a carbon source similar to that of the vein calcite. The $\delta^{18} \mathrm{O}$ values for vein 1 calcite are somewhat similar to those of both tufa- and land-snail carbonates. These similarities suggest water sources common to all. Tufa deposition is believed to have occurred at ambient temperatures from mineralizing springs derived from perched aquifers within the plateau which comprises a Tertiary succession of marine carbonates (Hassan 2012). The source water for the land snails on this plateau is rain (Hassan 2006).

\section{Conclusions}

The two types of vein calcite studied have carbon-isotope compositions within the range of primary carbon and could be related to a carbon source from the Sinn el-Keddab plateau. Calcite oxygen-isotope compositions, on the other hand, indicate low-temperature waters ranging from fresh (vein I) to slightly saline (vein II). These oxygen compositions, particularly those of vein I calcite, are consistent with formation from mineralizing waters isotopically similar to those of the Nubian aquifer or to modern rain. 
Acknowledgments. The author acknowledges the team of the "Toshki Uranium Study and Evaluation Project" for their field assistance, L. Wingate for stable isotope analyses, E.M. Abuzeid for taking the photomicrographs, and E.-L. Tullborg for providing literature from Sweden. I thankfully acknowledge the constructive comments and suggestions from the Editor (Marek Michalik) and two anonymous reviewers that significantly strengthen the article.

\section{References}

Al-Gamal, S.A. (1997). Hydrology of overland flow at Halaylb and Shelatin watersheds, Eastern Desert, Egypt. Turkish Journal of Engineering and Environmental Sciences, 21, 295-304.

Clayton, C.J. (1994). Microbial and organic processes. In A. Parker \& B.W. Sellwood (Eds), Quantitative diagenesis: Recent developments and applications to reservoir geology (pp.125-160). Kluwer Academic Publishers.

Clayton, R.N., \& Degens, E.T. (1959). Use of carbon isotope analyses of carbonates for differentiating freshwater and marine sediments. American Association of Petroleum Geologists Bulletin, 43(4), 890-897.

Craig, H. (1953). The geochemistry of stable carbon isotopes. Geochimica Cosmochimica Acta, 3(2-3), 53-92.

Craig, H., \& Gordon L. I. (1965). Deuterium and oxygen 18 variations in the ocean and the marine atmosphere In E. Tongiorgi (Ed.), Stable Isotopes in Oceanographic Studies and Paleotemperatures (pp. 9-130). Pisa:Consiglio Nationale delle Ricerche, Laboratorio di Geologia Nucleare.

Drake, H., \& Tullborg, E.-L. (2009). Paleohydrogeological events recorded by stable isotopes, fluid inclusions and trace elements in fracture minerals in crystalline rock, Simpevarp area, SE Sweden. Applied Geochemistry, 24, 715-732. DOI: 10.1016/j.apgeochem.2008.12.026.

Goldsmith, J.R., Graf, D.L. \& Heard, H.C. (1961). Lattice constants of the calcium-magnesium carbonates. American Mineralogist, 46, 453-457.

Hassan, K.M. (2005). Geochemical assessment of radioactive lava pockets in El-Seboah granite, Toshki area, south Western Desert, Egypt. Annals of the Geological Survey of Egypt, 28, 195-204.

Hassan, K.M. (2006). The stable isotopes of modern land snail shell from Sinn El-Kedab plateau, south west Aswan, Egypt. Isotope and Radiation Research, 38, 107-116.

Hassan, K.M. (2009). Characterization of granites by ${ }^{57}$ Fe Mössbauer spectroscopy. Mineralogia, 40(1-4), 95-106. DOI: $10.2478 / \mathrm{v} 10002-009-0008-x$.

Hassan, K.M. (2010). Valences and site characteristics of iron in radioactive magmatic veins (Egypt): A Mössbauer and chemical study. Mineralogia, 41(1-2), 23-33. DOI: 10.2478/v10002-010-0003-2.

Hassan, K.M. (2012). Fossil-spring tufa deposits capping a carbonate plateaux in the Dungul region (Egypt): A Stable Isotope and Geochemical Study. Submitted to Central Europe Journal of Geosciences.

List, F.K., El-Gaby, S., \& Tehrani, R. (1989). The basement rocks in the Eastern and Western Deserts and Sinai. In M. Hermina, E., Klitzsch \& S. List (Eds), Stratigraphic Lexicon and explanatory note to the geologic map of Egypt 1:500000 (pp. 33-56). Cairo, Egypt: Egyptian General Petroleum Corporation.

Kontak, D.J., \& Kerrich, R. (1997). An isotopic (C, O, Sr) study of vein gold deposits in the Meguma Terrane, Nova Scotia; implication for source reservoirs. Economic Geology 92(2), 161-180. DOI: 10.2113/ gsecongeo.92.2.161.

Larson, S.Á., \& Tullborg, E-L. (1984). Stable isotopes of fissure-filling calcite from Finnsjön, Uppland, Sweden. Lithos, 17, 117-125. DOI: 10.1016/0024-4937(84)90012-4.

Negga, H.S., Sheppard, S.M.F., Rosenbaum, J.M., \& Cuney, M. (1986). Late Hercynian U-vein mineralization in the Alps: fluid inclusion and $\mathrm{C}, \mathrm{O}, \mathrm{H}$ isotopic evidence for mixing between two externally derived fluids. Contributions to Mineralogy and Petrology, 93, 179-186.

Ripley, E.M., \& Taib, N.I. (1989). Carbon isotopic studies of metasedimentary and igneous rocks at the Babbitt Cu-Ni deposit, Duluth Complex, Minnesota, U.S.A. Chemical Geology, 73(4), 319-342. DOI: 10.1016/01689622(89)90025-0.

Said, R. (1969). Pleistocene Geology of Dungul Region, southern Libyan Desert. In J.J. Hester \& P.M. Hobler (Eds), Settlement patterns in the Libyan Desert (pp. 7-18). University of Utah Anthropological Papers, 92.

Sandström, B., \& Tullborg, E-L. (2009). Episodic fluid migration in the Fennoscandian Shield recorded by stable isotopes, rare earth elements and fluid inclusions in fracture minerals at Forsmark, Sweden. Chemical Geology, 266(3-4), 126-142. DOI: 10.1016/j.chemgeo.2009.04.019. 
Shemesh, A., Ron, H., Erel, Y., Kolodny, Y., \& Nur, A. (1992). Isotopic composition of vein calcite and its fluid inclusions: Implication to paleohydrological systems, tectonic events and vein formation processes. Chemical Geology, 94(4), 307-314. DOI: 10.1016/S0009-2541(10)80032-4.

Sultan, M, Sturchio, N., Hassan, F.A., Hamdan, M.A.R, Mahmood, A., El Alfy, Z., \& Stein, T. (1998). New constraints on the Quaternary paleoclimate of North Africa. Proceedings of the Egyptian Geological Survey Centennial Conference, November 19-22, 1996 (pp. 809-820). Cairo, Egypt.

Truesdell, A.H., \& Hulston, J.R. (1980). Isotopic evidence on environments of geothermal systems. In P. Fritz, \& J.C. Fontes (Eds.), Handbook of Environmental Isotope Geochemistry (pp.179-219). Amsterdam: Elsevier.

Tullborg, E.-L. (1989). The influence of recharge water on fissure-filling minerals - A study from Klipperås, southern Sweden. Chemical Geology, 76, 309-320. DOI: 10.1016/0009-2541(89)90099-5.

Valero-Garcés, B. L., Delgado-Huertas, A., Ratto, N., \& Navas, A. (1999). Large ${ }^{13} \mathrm{C}$ enrichment in primary carbonates from Andean Altiplano lakes, northwest Argentina. Earth and Planetary Science Letters, 171(2), 253-266. DOI: 10.1016/S0012-821X(99)00150-8. 